Impact Factor $7.105 \div$ Vol. 9, Issue 1, January 2022

DOI: 10.17148/IARJSET.2022.9103

\title{
A Review of Automatic Cleaning Systems for Photovoltaic Solar Panels
}

\author{
Ahmed Ammar Kalaji ${ }^{1}$, Ayman Salah Abbas², Mahmoud Magdy ${ }^{3}$ \\ Engineer, Renewable Energy, The British university in Egypt, Cairo, Egypt ${ }^{1}$ \\ Professor, Mechanical Engineering, The British university in Egypt, Cairo, Egypt ${ }^{2}$ \\ Assistant Professor, Mechanical Engineering, The British University in Egypt, City, Egypt ${ }^{3}$
}

\begin{abstract}
Many factors effect on the efficiency of the photovoltaics panels such as soiling, environment, the design of the panel and even if the whole system includes a tracking mechanism. Taking into consideration the previous factors will allow the panel to give the maximum possible power. The accumulated dust and dirt over the photovoltaics panels will stick over it and will act like a shield preventing the rays from the sun to hit the surface of the panels. The studies shows that the panels will decrease more than $30 \%$ because of the dust accumulation. That is why the panels must be cleaned regularly. This paper provides a review of the dust problem as well as recent developments in automated solar photovoltaic module cleaning systems, including a short overview of techniques such as electrical, mechanical, chemical, and electrostatic cleaning. The study's main goal is to conduct a literature review on solar photovoltaic module automated cleaning techniques in order to identify research gaps in automated cleaning systems.
\end{abstract}

Keywords: Solar panel cleaning, dust accumulation, cleaning techniques, Photovoltaic performance

\section{INTRODUCTION}

In the last 20 years, the world starts to focus on renewable energy as future demand for energy. This led to a huge increase of interest in the solar energy field in the shape of the photovoltaic cells as it is a clean source of power. That focusing on photovoltaic power caused an increase in research and development in this area. The European Union announced that in 2013 3\% of the consumed power inside the union was from solar energy that 3\% represents 80 terawatt-hours of electricity and the number is increasing. Also, according to IRENA Egypt as an example of a developing country had more than $3200 \mathrm{MW}$ worth of solar energy power projects pending or under construction. This proves that the world and the developing countries are heading into green efficient solar panel energy way very soon. As photovoltaic energy becomes one of the popular ways for energy production makes the investment institutions, companies, residential users, and governments start to install it to benefit from it. Therefore, this increase in the photovoltaic energy demand encourages the research for increasing the output energy produced by the phot systems which led the laboratories around the world to work and focus on producing a photovoltaic panel that can be considered as power-efficient and can be costeffectively considered.

Although there is a huge of effort to decrease the time of the payback of the photovoltaic systems, the losses in the output power in the real operation time cannot be neglected and cannot be prevented. These losses occur because of many reasons such as soiling. Soiling is when a layer of dirt accumulates over the glass of the photovoltaic solar panels which in turn causes a reduction in the transmittance of the glass. This reduction decreases the output power of the entire photovoltaic system. The amount of power reduction regarding the accumulated dust cannot be predictable as it is depending photovoltaic many factors came from the environmental situations, type of soil near the system, the farming activities near the panels, wind, and bird traveling in the area. The average loss came from the accumulated dust and dirt over the panels is $4-9 \%$ but in the sandy and dry climates can reach $30-45 \%$ losses in the output power in the solar systems. Raining and the accumulated dew over the panels play a role in cleaning the panels but cannot be depending on as in some areas the rain is infrequent. Also, some of the soil-cement and dust stick on the panels and can be removed depending on the rain. 


\section{International Advanced Research Journal in Science, Engineering and Technology \\ Impact Factor $7.105 \div$ Vol. 9, Issue 1, January 2022 \\ DOI: $10.17148 /$ IARJSET.2022.9103}

The output power of the photovoltaic solar panel's systems increases when the radiation of sunlight increases. So, in recent years the number of Photovoltaic solar panels solar panels systems installed in places close to the equator line increased. These regions are known for the dry climate and sandy air which increase the accumulated dust over the photovoltaic solar panels and reduce the energy output of the systems. As the systems get close to the equator line the effect of the soiling on the photovoltaic cells increases because of the small tilt angles that the systems are installed with. The manufacturers of the photovoltaic solar cells are concerned about the incident angle of the sunlight to ensure maximum light goes to the panels. as the sunlight cannot be controlled the soiling effect is what can be managed. Consequently, in the desert regions or the sandy regions the photovoltaic solar panels systems need more cleaning than the other regions, so many methods had been found for preventing or minimizing the effect of the soiling on the output power of the photovoltaic solar cells systems.

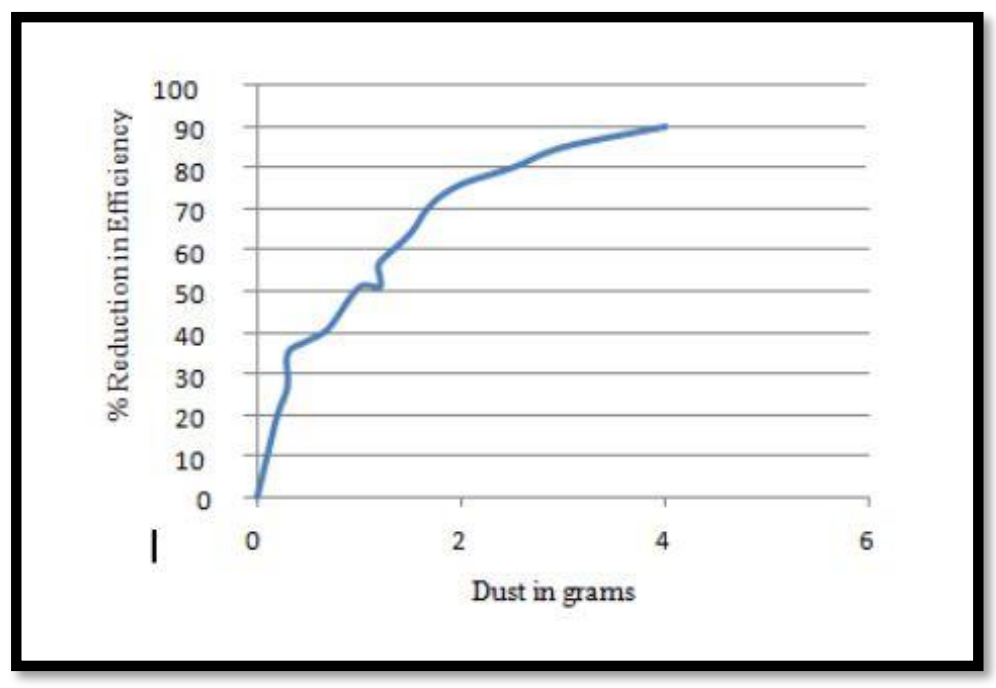

Figure 1Dust in grams versus Reduction in efficiency [4]

The graph shows the effect of the accumulated dust over the photovoltaic solar cells system on the efficiency of the system. Which shows the decreasing amount of efficiency per gram of dust.

Moreover, in some conditions in harsh environments, some weather conditions might result in an excessive reduction in efficiency in Photovoltaic cells. Research that was conducted in Egypt was meant to study the effect of the weather on solar panel cells efficiency in new Cairo. It was found that high temperature can reduce the generated electrical power by up to $10 \%$ while accumulated dust can lead to over $30 \%$ of efficiency loss. It is worth mentioning that both are directly related to accumulated dust affecting the temperature of the solar panels. The reason behind this is that it creates a layer that reduces the effectiveness of air cooling for the panels which results in increasing heat upon the panels and lowers the efficiency even more. After one month of not cleaning the solar panels can lose up to half of their efficiency which is very crucial for the process and calls for an urgent necessary solution.

\section{LITERATURE REVIEW}

Photovoltaic solar panels nowadays exist in most parts of the world. A lot of the time the efficiency of these photovoltaic solar panels drops without even aging, this drop in efficiency is caused by a sudden reduction of transmittance. Reducing the transmittance of the photovoltaic solar panels is a result of the accumulated dust, mud, or gravel over the panel surface. This causes a reduction in the power output which leads to a reduction in the power generation of the power plant which by turn affects the electricity production and also reduces income. The accumulated dust over the panel decreases the lifespan of many space explorations such as the Mars exploration mission. The mission was to face this problem because of the dust and because there is a dire need for this issue to be solved by any means for its massive unwanted effect. In addition, the dust accumulation problem results in a huge power loss for the solar plant that suffers from the frequent and infrequent dusty sandy storms, sandy environment, muddy environment, and even close to cities. 


\section{International Advanced Research Journal in Science, Engineering and Technology \\ Impact Factor $7.105 \div$ Vol. 9, Issue 1, January 2022 \\ DOI: $10.17148 /$ IARJSET.2022.9103}

$\underline{\text { Removal of dust using labours or flipping methods }}$

The most common method of cleaning the solar panels is manually using labour and giving them multiple tasks at the same time. However, with neglecting the time wasted in cleaning the panels as manual cleaning takes a long time, cleaning the panel is also risky because fatal damage could happen to the expensive photovoltaic solar panels modules due to the unprofessional and unqualified laborers who involved in the process. Another problem related to the weather which may put the labour in danger too due to the existence of most solar farms in extremely hot areas which might put the labour in danger of heatstroke and other hazards. The labour must be in a team that has a supervisor by some qualified person. This scheme will highly increase the maintenance cost and it will also create a hazardous chance for both the photovoltaic panels and for the labour. Human errors will affect the probability of imperfection of manual cleaning. This will cause again some losses in the output power generation. Also, manual cleaning has some risks on the labour life as working in cleaning the solar panel manually required working in high levels over the ground which increases the possibility of falling. Similarly, the connection wires could cause electric shaking for labours. The safety insurance that must be taken will increase the cost of the cleaning. However, the reason to pick this type over the others is that there are

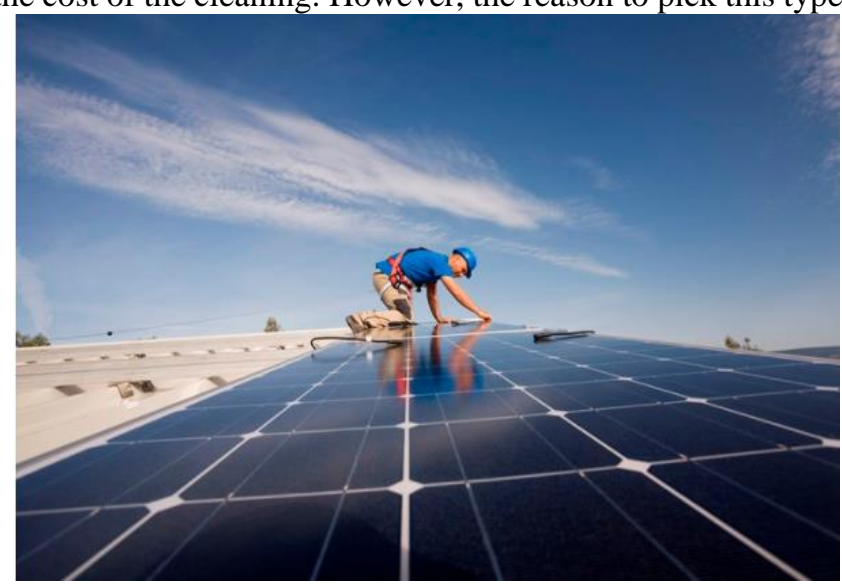

Figure 2 A person cleaning PV panels manually [16]

types of solar panels that has been mounted in irregular patterns or having irregular shapes for research reasons or just because they were outdated farm pattern. The irregular shapes that are sometimes used to generate electricity cannot usually be cleaned by regular automated cleaning machines and thus manual labour might come in handy in this case.

Natural cleaning of solar panels is done using natural provided techniques to remove dust using wind, gravity, and rainwater. Usually, in real life, the practical use of this technique is accomplished by flipping the solar panels using the tracking mechanism to 90 degrees or even 180 degrees to let the gravity pull the particles off the surface of the panels. A study was conducted by where this method was performed proving that it is possible, however rotating a large solar panel is very difficult and requires a lot of electricity. It is also worth mentioning that a lot of types of dust and impurities and soil sometimes stick to the surface with makes it very difficult to remove them only using gravity.

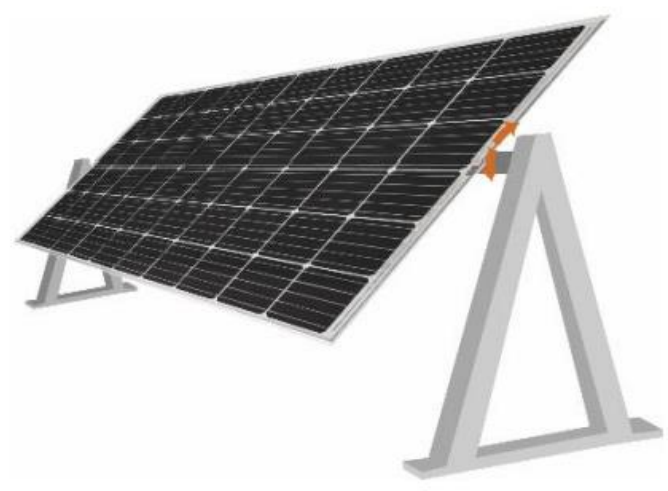

Figure 3 Photovoltaic cell flipping mechanism [17] 


\section{International Advanced Research Journal in Science, Engineering and Technology \\ Impact Factor $7.105 \div$ Vol. 9, Issue 1, January 2022 \\ DOI: $10.17148 /$ IARJSET.2022.9103}

\section{Removal of dust using material coating method}

A layer of a transparent Nano-film is capable to do the self-cleaning for the solar panels, as the layer cleans the surface autonomously. The cleaning strategies that the Nano-film use is based on two main strategies, the SuperHydrophilic Material and Super - Hydrophobic Materials.. Coating thickness effect the amount of the power output as coating will decrease the transmittance of sun light but the study shows that at $80 \%$ better than the $60 \%$ as the coating play a role in cooling the surface of the photovoltaics panels.

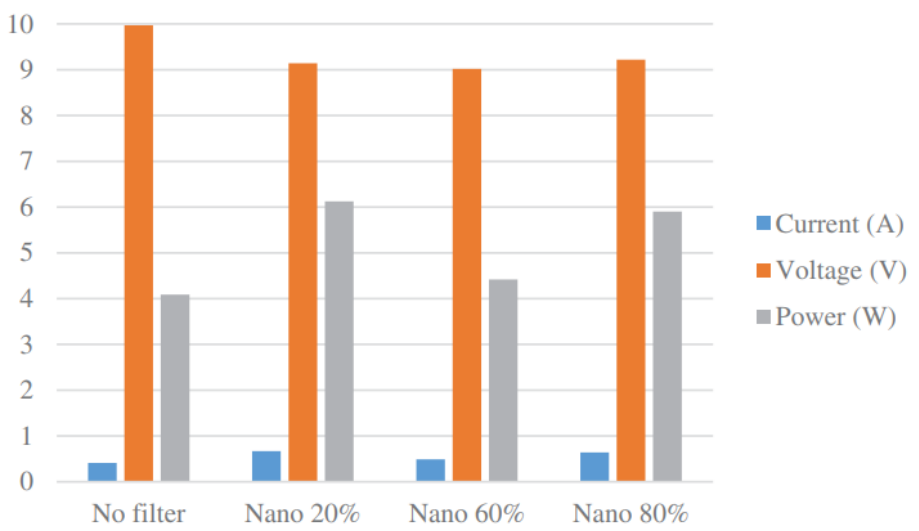

Figure 4 Variation of (Voltage, Current and power) of photovoltaic solar panels with nano film and without [7]

Super-Hydrophilic materials are known for their strong ability to attract water molecules. The most known material of super hydrophilic is titanium dioxide $\left(\mathrm{TiO}_{2}\right)$ which has the properties of hydrophilic and photocatalytic. This technique works in two stages. First one is that when the ultraviolet light hits the layer of the $\mathrm{TiO}_{2}$ the layer reacts with it to split the dust organic matters. The second one, when the rainwater fails the hydrophilic nature of the $\mathrm{TiO}_{2}$ will diffuse the water over the solar panel that will remove the dust from all over the panel. However, this method in most situation is not suitable as most of the solar power plant is installed in an arid area that the raining water is rare.

The main properties of the superhydrophobic material are the high ability to repulse the water molecules. The use of this material was taken because of nature evidence of the lotus leaves that has very small wettability. By forming a microstructure and Nanostructure of the hydro-phobic material lots of studies in recent times are trying to conduct and replicate such material. These structured are designed to increase the contact angle to a very high angle like 150 degrees and more. This will result that the water drops will fall on this type of material taking or carrying all the inorganic and organic dust with them. That will ensure automatic self-cleaning for the photovoltaic panels. However, this method in most situations is useless as most solar power plant is installed in an arid area that the raining water is rare. Also, such material needs more studies and research to ensure the feasibility and ability in such application.

$\underline{\text { Removal of dust using Electro-Static methods }}$

The electro-static cleaning technique had been developed and invented based on the electric curtain concept that been founded in the late sixties in the last decade. Following this, the University of Tokyo did another development in this technique. In this technique, the electrostatic forces are used to increase and transport the uncharged and the charged particles. Technology in recent years lot of the research tried to apply it in the space applications such as the rovers that could be sent to the moon and mars for explorations. This technology uses parallel conducting electrodes in series that are embedded in the dielectric surface. Across the surface, any oscillation will be transmitted between the potential of the electrodes. shows the structure of electrostatic cleaning coat where the electrodes technically create a moving static curtain that removes particles off the surface.

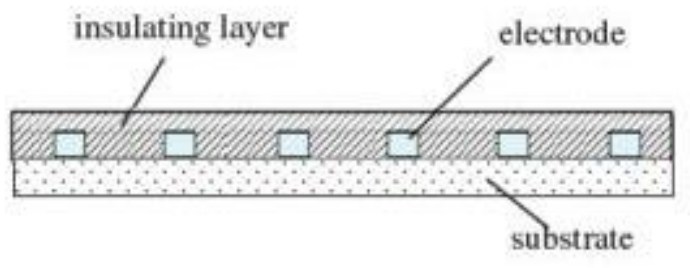

Figure 5Basic Structure of Electric Curtain [9] 


\section{International Advanced Research Journal in Science, Engineering and Technology \\ Impact Factor 7.105 Vol. 9, Issue 1, January 2022 \\ DOI: 10.17148/IARJSET.2022.9103}

Connecting the electrodes to AC single-phase voltage will generate a standing wave field. Researchers believed that this standing wave field will generate a self-cleaning mechanism by floating the particles. But this wave is not enough to transport the particles away from the solar panel surface. So, connecting the electrodes with multi-phase AC voltage will generate the floating mechanism and will generate a traveling wave for the particle. By properly connecting the voltage the traveling wave will throw the particles away from the solar panel's surface. This mechanism could be considered as an automatic self-cleaning mechanism for photovoltaic solar panels. But, the main disadvantage of using electrical methods to clean the accumulated dust over the photovoltaics panels that it use electricity as in the begging the main purpose of using photovoltaics panels is to generate electricity.

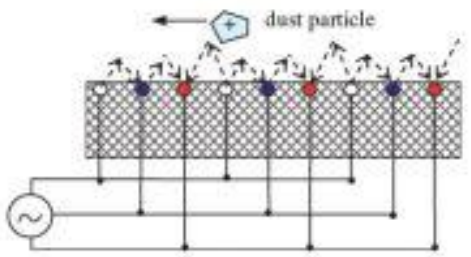

Figure 6 Three Phase Electric Curtain [9]

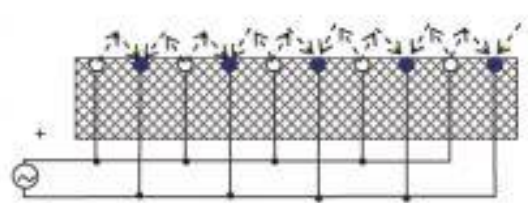

Figure 7 Single Phase Electric Curtain [9]

Removal of dust using mechanical methods

Truck mounted technique is based on brushes connected to a truck or a vehicle, the truck can be driven by the driver between the photovoltaic modules rows. By using a crane jib that carries the brushes the brushes will be able to be placed over the photovoltaic modules. To avoid damaging the photovoltaic modules each machine or vehicle has its controlling system to control the pressure over the photovoltaic modules. The distance between the modules and the tilt angle of the module is not considered a problem in this type of cleaning mechanism. But the distance between the photovoltaic modules rows must maintain a minimum distance that allows the vehicle to move between the rows. The distance between the row depends on the range of the crane which on average is about 2.5 to 3 meters. Also, the area of manoeuvring at each row end must be enough to allow the vehicle to turn around and move to the next row.

The manufacture of the photovoltaic modules must give the tolerance of the allowed weight that the brushes can apply over the photovoltaic modules. The mechanism of the truck-mounted increase the risk of damaging the photovoltaic modules because of the ground irregularity that could cause the brushes to do extra pressure on the photovoltaic modules. This could result in the cells and the modules lifetime being affected. Specially trained labour is required to drive the cleaning mounted truck. Usually, the required training is provided by the manufacturer of the equipment. The place where the worker sit must be air-conditioned to ensure the proper work conditions for the worker. Also, most of the truckmounted equipment is equipped with a spotlight that allows the cleaning process to be done at night. SunBrush Mobil $\mathrm{GmbH}$ and BP Metalmeccanica can be taken as two examples of the companies that manufacture such systems.

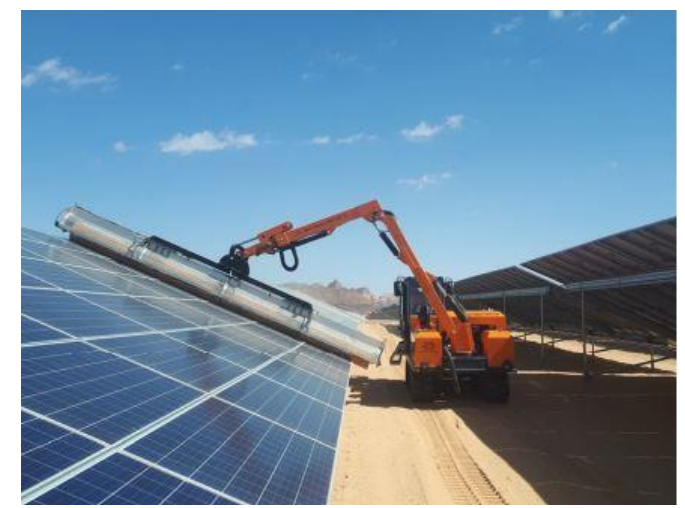

Figure 8 BP Metalmeccanica telescopic cleaning device [10]

Each row of the photovoltaic modules must have it is own semi-automated cleaning device. The device will move automatically with only one direction over the surface of the photovoltaic module. Then the device is carried by hands after completing the table of photovoltaic modules to the next photovoltaic module. Generally, the mechanism is connected to a sensor to detect the end of each row to make the mechanism back to the beginning point automatically. The traction of the mechanism in most of the designs uses the photovoltaic module surface or the frame of the photovoltaic modules to move. This type of device can be installed over the photovoltaic modules after the construction of the photovoltaic modules be done without facing difficulties. This type of cleaning mechanism also requires that the modules 


\section{International Advanced Research Journal in Science, Engineering and Technology \\ Impact Factor $7.105 \div$ Vol. 9, Issue 1, January 2022 \\ DOI: $10.17148 /$ IARJSET.2022.9103}

do not have any gaps between each other related to tilt angles and the modules are installed along with arrays. The number of cleaning devices could be reduced by installing the photovoltaic modules in long arrays. But this device cannot overcome the different tilt angles and the gaps between the modules. Each semi-automated device has its limitations to overcome such factors.

The movement across the photovoltaic modules arrays should be smooth to ensure no damage occurs to the modules. Semi-automated cleaner operates with a battery that takes place onboard the device. One of the advantages of semiautomated devices is that when the device is not needed it can be stored in a safe environment to ensure and increase its lifetime. These cleaning mechanisms required a minimum of two workers to move the device from one row to another. But the cleaning happens automatically by the device. These semi-automated cleaning devices are produced by many companies, a good example of that is .

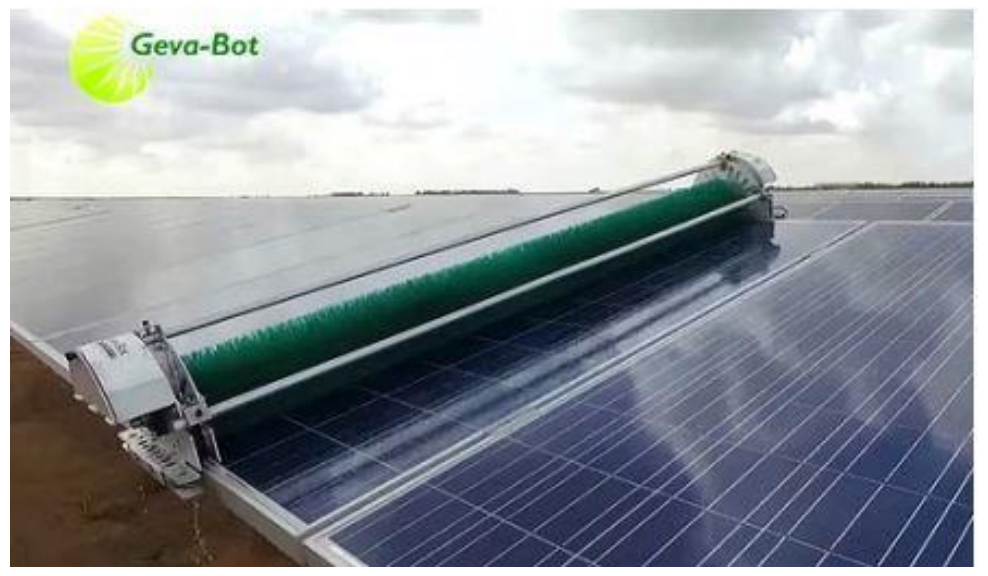

Figure 9Geva-Robot from G.S.I. during module cleaning [11]

A fully automated cleaning mechanism can be installed for a row of the photovoltaic systems rows and parked in a parking station at the end of each array. The mechanism is designed to be applied only in a single row. These mechanisms take into consideration the weather conditions and detect the errors before start cleaning the photovoltaic systems. Like the semi-automated systems, the fully automated carry its battery on board, and some devices could have their photovoltaic system to charge the battery. The fully automated mechanism requires the installation of an additional rail system to move through it. Also, must consider any obstructions between the photovoltaic tables as (tilt angle, steps, and spaces). As the name shows the fully automated mechanism operates without any help of human hands in the cleaning, moving, positioning, and processing. Also, most of the system can operate at night.

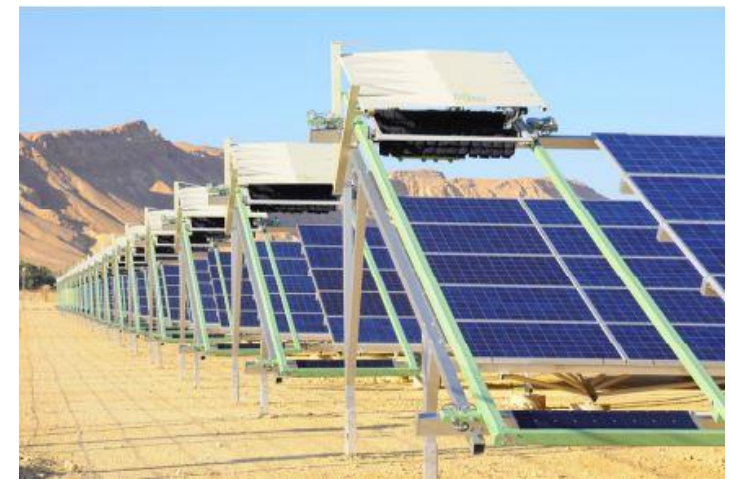

Figure 10Fully automated cleaning system [13]

The portable robot is a device that over the photovoltaic modules with dimensions about one square meter. The robots have sensors to control the movement over the surfaces and detect the edges of the photovoltaic modules and move from side to side over the array surface to clean. Some robots can be driven remotely by labours. Most of the robots have limitations with minimizing the ability to use it in cleaning the photovoltaic modules. The limitations are caused by the tilt angle as some robots cannot be operated with an angle of more than 15 degrees. Other robots have their bodies stick over the photovoltaic modules by using a vacuum which allows to clean photovoltaic modules with tilt angles that approach 75 degrees. This type of cleaning mechanism is mostly used with photovoltaic systems and trackers installed over the rooftop of buildings. 


\section{International Advanced Research Journal in Science, Engineering and Technology \\ Impact Factor $7.105 \div$ Vol. 9, Issue 1, January 2022 \\ DOI: $10.17148 /$ IARJSET.2022.9103}

Air cleaning, as the air is free and exists everywhere, which makes air solutions sound very promising. The use of air to clean photovoltaic cells is one of many solutions to clean photovoltaic cells surfaces. Usually, normal airflow cannot clean photovoltaic cells by itself, thus, to make this solution viable an air compressor is used to blow off dust and soil off the surface of the photovoltaic cell, this technique is widely used around the world not only in photovoltaic cells, but people also use it almost in most cleaning applications. This problem however has some drawbacks. Air cleaning might be time-efficient and kind of cost-efficient too. Many studies were conducted to test this technique, a study that was made by $\mathrm{Li}$ for example, tested this technique and proved that air cleaning does improve the photovoltaic panel efficiency and power generation, and it also cools it down which by turn also increases the power generated.

One of the advantages of this technique is that it is extremely simple where a compressor will simply turn on and blow all the dust off the surface. This technique also does not direct the air or any kind of additional motion or actuation where a nozzle shaped so the air can reach all the panel surface can simply do that. Another advantage is that it does not need a reservoir like water because air is everywhere and free.

However, the use of air blowers to clean the surfaces of photovoltaic panels does not guarantee the removal of all solid objects from the photovoltaic cell surface. The reason behind that is some kinds of soil as mentioned before sticking to the surface and cannot be removed. Another drawback is Compressors usually use a lot of electricity which causes some doubt about their viability. It is also worth mentioning that a mechanism like that might be heavy and hard to move which makes this technique doubtable.

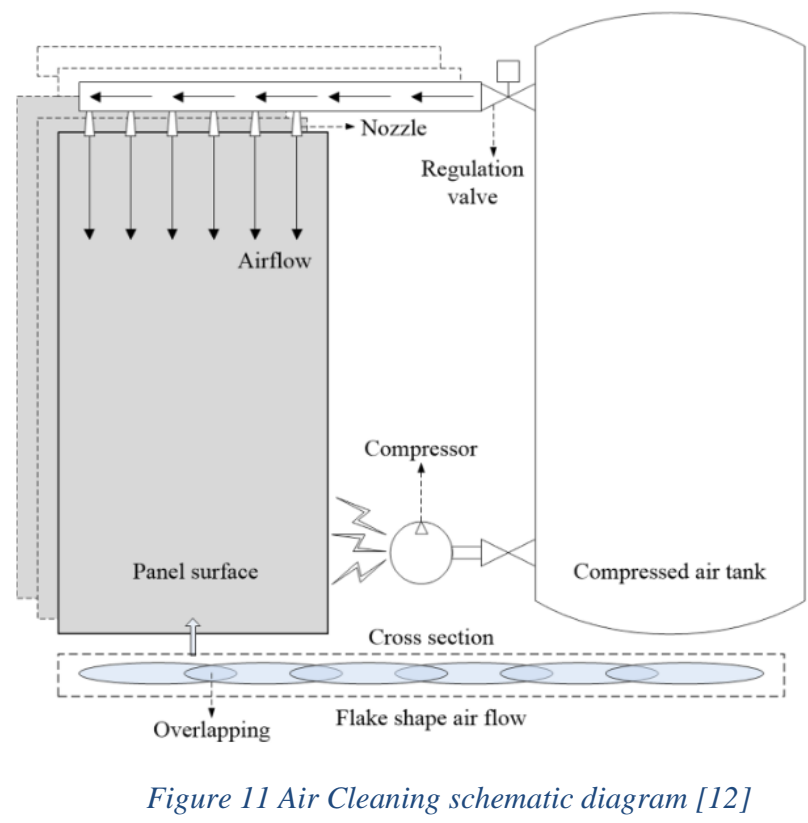

A lightweight robot-made company called Solarbrush developed a robot suitable for dry cleaning of solar panels. that clean solar panels by using suction cups. the robot moves over the panels with the possibility to overcome $30 \mathrm{~mm}$ gaps and be able to work over an inclined surface with a maximum inclination of 35 degrees. The robot can be attached to a brush installed in front of the robot to brush the dust and the sand away. The robot is powered by a rechargeable battery. One of the advantages of this robot includes being small in size which may be beneficial production and transportation-wise. Also, being autonomous is a great advantage for users to save time and energy.

However, the disadvantages on the other hand include a maximum tilt angle of 35 degrees, using batteries, being expensive, and sometimes they need for the operator to charge it and to store it. 


\section{International Advanced Research Journal in Science, Engineering and Technology \\ Impact Factor $7.105 \div$ Vol. 9, Issue 1, January 2022 \\ DOI: 10.17148/IARJSET.2022.9103}

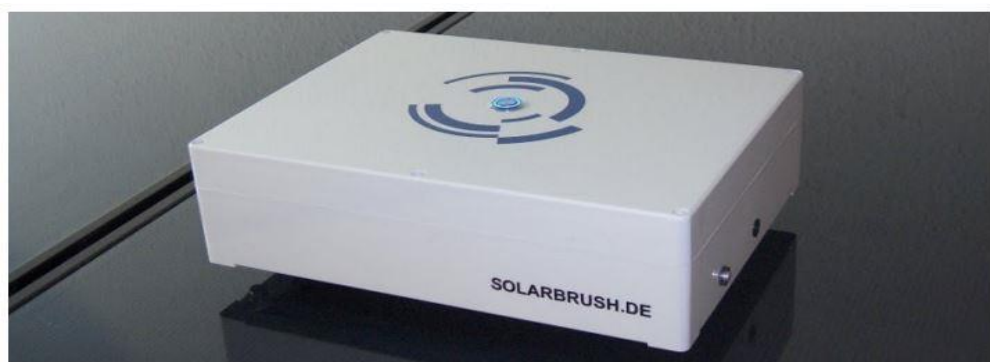

Figure 12 The Solarbrush robot without its brush. [19]

Ecoppia E4 robot autonomously brushes the dust over the panels. the Ecoppia E4 was designed for large-scale solar panels that suited in sandy and dry environments. Airflow is generated by using gravity that moves the brush downwards and spins over the panels that helping blow the dust and the sand off the panels.

A frame of guide rail the robot moves horizontally and vertically by using wheels. The robot operates by saving power from the output power from panels and saving it in a rechargeable battery that allows the robot to operate overnight. While the robot moves downward an energy recovery system activates to gain power from the movement. This system can be seen in Figure 13 while its pros and Cons are shown in .This design has many advantages including energy-saving, autonomous cleaning, low running cost. However, it also has disadvantages such as being needs construction work and having a high initial cost.
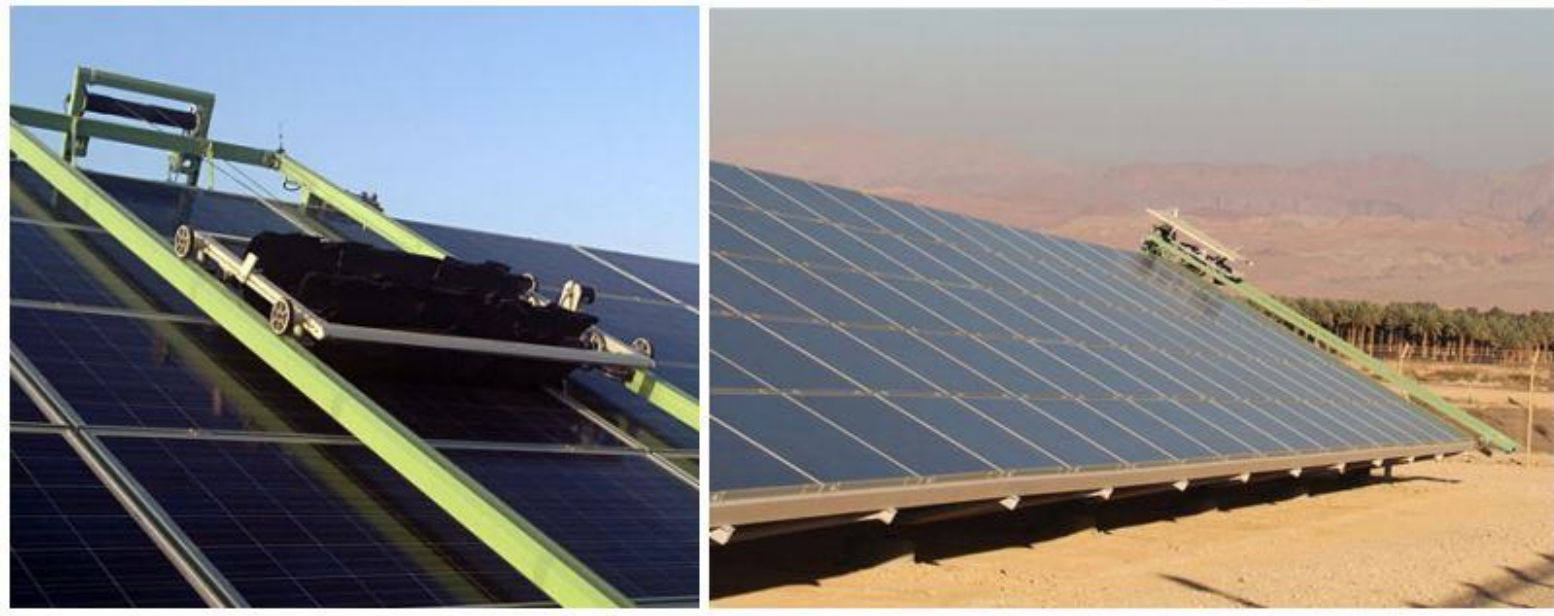

Figure 13 Ecoppia E4 [13]

Wash panel companies in Italy developed a robot that cleans the solar panel arrays by using a vertical brush that moves horizontally over the solar panels. The robot can be customized for an array with 1 to 16 meters in length by using a 12-volt battery. For wetting the panels, a hose is attached to the robot to help while cleaning. The robot does not need track lines like most of the panels. This design is considered a heavy-duty system, autonomous system and can use

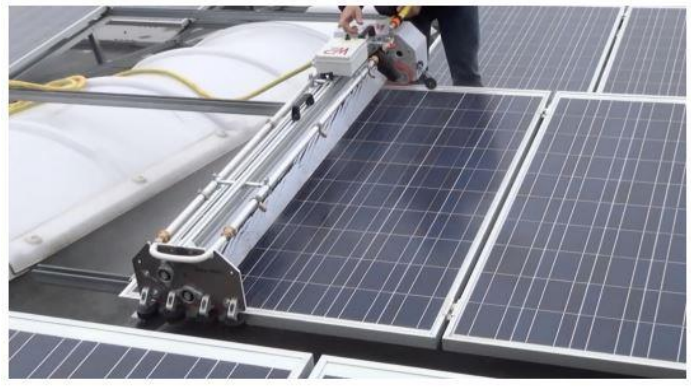

Figure 14An example of a 'Wash Panel' system 


\section{International Advanced Research Journal in Science, Engineering and Technology \\ Impact Factor $7.105 \div$ Vol. 9, Issue 1, January 2022 \\ DOI: $10.17148 /$ IARJSET.2022.9103}

water for cleaning. On the other hand, this design can only be used for a one-row set of panels and must be custom made, it can also be expensive and have a limited tilt angle.

Depending on the nozzles distributed around the system and the panel could be covered with a chemical coat that resists the water then the water takes the dust and go down. This process can be shown in Figure 15. This cleaner is small in size, highly autonomous, and can have a low wear rate over time. On the other hand, it sometimes needs maintenance, uses a lot of water, might be less effective in some regions than in others

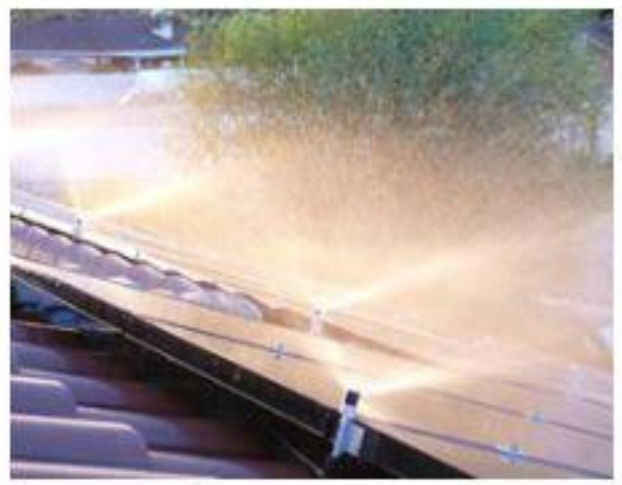

Figure 15 Heliotex sprinkler system

\section{CONCLUSION}

In conclusion, cleaning photovoltaic panels has been done before either using dry, wet, or combined cleaning techniques. However, wet cleaning is probably not a very fitting solution in many cases. This goes back to its high cost and maintenance need, in addition to other factors. Dry cleaning on the other hand is considered cost-effective and cleaning effectively too. There are many cleaning techniques in the literature, only a few of them fit the harsh work conditions desired, same goes for existing cleaning systems, for this reason, it is needed to fabricate and design a system that solves these issues.

\section{REFERENCES}

[1] A. Q. R. A. M. D. D. Bernd Webera, "Performance Reduction of PV Systems by Dust Deposition," Energy Procedia, 2013.

[2] IRENA, "Renewable energy outlook in Egypt," p. 28, 2018.

[3] M. Kegeleers, "The development of a cleaning robot for PV panels," TECHNOLOGY CAMPUS DE NAYER, 2015.

[4] P. A. ,. Ananthi. K, "Increasing the efficiency of Solar Panels,” International Journal of Pure and Applied Mathematics, 2018.

[5] E. Elshazly, A. Abd El-Rehim, A. Abdel-kader and I. El-Mahallawi, "Effect of Dust and High Temperature on Photovoltaics Performance in the New Capital Area," WSEAS TRANSACTIONS on ENVIRONMENT and DEVELOPMENT, 2021.

[6] NASA, “Aeolian Removal of Dust Types From Photovoltaic Surfaces on Mars,” 1990. [Online]. Available: https://ntrs.nasa.gov/api/citations/20150022872/downloads/20150022872.pdf.

[7] A. Manasrah, A. Zyoud and E. Abdelhafez, "Effect of color and nano film filters on the performance of solar photovoltaic module," 2019.

[8] R. James and E. Marla, "Aeolian Removal of Dust Types From Photovoltaic Surfaces on Mars," in 16th Space Simulation Conference, 1990.

[9] G. He, C. Zhou and Z. Li, "Review of Self-Cleaning Method for Solar Cell Array," 2011.

[10] BP Metalmeccanica ,"SOLAR CLEANER F3500 Telescopic," [Online]. Available: https://eng.bpmetalmeccanica.com/macchine-pulizia-pannelli-solari/solar-cleaner-f3500-telescopic.html.

[11] Geva BOT, [Online]. Available: https://www.geva-bot.com/.

[12] D. Li, M. King, M. Dooner, S. Guo and J. Wang, "Study on the cleaning and cooling of solar photovoltaic panels using compressed airflow," Solar Energy, pp. Pages 433-444, 2021,.

[13] 2021. [Online]. Available: https://www.ecoppia.com/. 


\section{International Advanced Research Journal in Science, Engineering and Technology}

\section{Impact Factor 7.105 ㄷ Vol. 9, Issue 1, January 2022}

\section{DOI: 10.17148/IARJSET.2022.9103}

[14] D. Deb and N. L. Brahmbhatt, "Review of yield increase of solar panels through soiling prevention, and aproposed water-free automated cleaning solution," Renewable and Sustainable Energy Reviews, pp. 3306-3313, 2018.

[15] D. Deb and N. L. Brahmbhatt, "Review of yield increase of solar panels through soiling prevention, and aproposed water-free automated cleaning solution," Renewable and Sustainable Energy Reviews, pp. 3306-3313, 2018.

[16] L. Barry, "How to clean solar panels," 2021. [Online]. Available: https://www.bhg.com.au/how-to-clean-solarpanels-from-the-ground.

[17] S. Seme, B. Štumberger, M. Hadžiselimovi'c and K. Sredenšek, "Solar Photovoltaic Tracking Systems for Electricity Generation: A Review," MDPI, 2020.

[18] M. Grando, E. Maletz and D. Martins.

[19] M. Grando, E. Maletz and D. Martins, "Robots for Cleaning Photovoltaic Panels: State of the Art and Future Prospects," 2017. 